\title{
Flexible Adsorbents at High Pressure: Observations and Correlation of ZIF-7 Stepped Sorption Isotherms for Nitrogen, Argon and Other Gases
}

\author{
Xiaoxian Yang ${ }^{1}$, Arash Arami-Niya ${ }^{1,2}$, Gongkui Xiao ${ }^{1}$, Eric F. May ${ }^{1, *}$ \\ ${ }^{1}$ Fluid Science \& Resources Division, Department of Chemical Engineering, University of \\ Western Australia, Crawley, WA 6009, Australia \\ ${ }^{2}$ Discipline of Chemical Engineering, Western Australian School of Mines: Minerals, Energy \\ and Chemical Engineering, Curtin University, GPO Box U1987, Perth, WA 6845, Australia
}

\begin{abstract}
Stepped adsorption isotherms with desorption hysteresis were measured for nitrogen, argon, ethane, carbon dioxide and methane at pressures up to $17 \mathrm{MPa}$ on zeolitic imidazolate framework-7 (ZIF-7) using a gravimetric sorption analyzer. Such stepped sorption isotherms have not been previously reported for nitrogen or argon on ZIF-7, and required the application of pressures as high as $15 \mathrm{MPa}$ to trigger the ZIF-7 structural phase transition at temperatures around at $360 \mathrm{~K}$. The stepped hysteretic sorption isotherms measured for carbon dioxide, methane and ethane were consistent with previous observations reported in the literature. To correlate these stepped hysteretic sorption isotherms, a semi-empirical model was developed by combining a threeparameter Langmuir equation to describe the Type I aspect of the isotherm, with a six-parameter model used to describe the temperature-dependent ZIF-7 structural phase transition. Excellent fits of the combined adsorption and desorption branches were possible with the temperature-dependent night-parameter model, with root-mean-square deviations within $2.5 \%$ of the highest measured adsorption capacity. Each parameter of the new semi-empirical model has a physical basis, allowing them to be estimated or compared independently.
\end{abstract}

Keywords: correlation model, stepped sorption isotherm, hysteresis, phase transition, zeolitic imidazolate framework-7

"Corresponding author. Email address: eric.may@uwa.edu.au. 


\section{Introduction}

Metal-organic frameworks (MOFs) are an emerging class of three-dimensional porous materials composed of metal ions and organic linkers. ${ }^{1}$ Varying the metals, ligands and linkers in MOFs makes it possible to tune their structure and control their pore connectivity, dimension and functionality. Compared with other porous materials, including activated carbon, silica and zeolite, the tunable structure of MOFs makes them promising in different applications such as gas storage and separation, ${ }^{2-3}$ liquid separation ${ }^{4}$ and drug delivery. ${ }^{5}$ Particular types of MOF show reversible structural flexibility as a response to external stimuli, such as pressure and temperature. ${ }^{6}$ These flexible MOFs generally possess unique stepped gas adsorption isotherms, which exhibit a distinctive adsorption uptake curve with a small increase at low pressure, followed by a rapid, abrupt rise or "step" in sorption capacity over a narrow pressure range, with a near-plateau in capacity occurring at high pressure. Desorption hysteresis is also generally observed, i.e., the sorption capacity steeply drops in another narrow pressure range below that of the rapid rise in the adsorption branch. ${ }^{7}$

Typical examples of stepped hysteretic sorption isotherms are depicted in Figure 1, which shows the sorption isotherms, measured in this work, of nitrogen, argon, carbon dioxide and methane on a flexible MOF sample: zeolitic imidazolate framework-7 (ZIF-7). The drastic change in sorption isotherms of flexible MOFs can lead to enhanced selectivity of gases, high usable gas storage capacities, and reduced thermal management requirements, ${ }^{6,10}$ which makes them useful in many applications. For example, in gas storage applications, the operational range of working pressures could be significantly reduced thereby lowering the energy consumption and cost of the process. For gas separation applications, differences in the location of the step in the sorption isotherm for different gases (as shown, for example in Figure 1 for ZIF-7) could give rise to a high selectivity upon which to design the separation process.

Stepped hysteretic sorption isotherms at ambient temperature have been reported previously for several pure gases on various MOFs. For example, Mason et al. ${ }^{11}$ reported the stepped adsorption of methane on $\mathrm{Fe}(\mathrm{bdp})$ and $\mathrm{Co}(\mathrm{bdp})$ and suggested the sudden increase in methane uptake was caused by the structural phase transition of the adsorbents at specific pressures. McDonald et al. ${ }^{12}$ showed stepped adsorption isotherms for carbon dioxide on mmen- $\mathrm{Mg}_{2}$ (dobpdc) and associated the increased capacity with a phase transition in the adsorbent from a dynamic surface state to a well-ordered extended surface structure. Arami-Niya et al. ${ }^{10}$ reported the anomalous adsorption of methane on ZIF-7, which at low pressures has a nominal crystallographic pore diameter of only $2 \AA$. They proposed that a gate opening phase transition occurred at higher pressures, which then allowed the adsorption of guest molecules with kinetic diameters of up to $5.2 \AA$. 


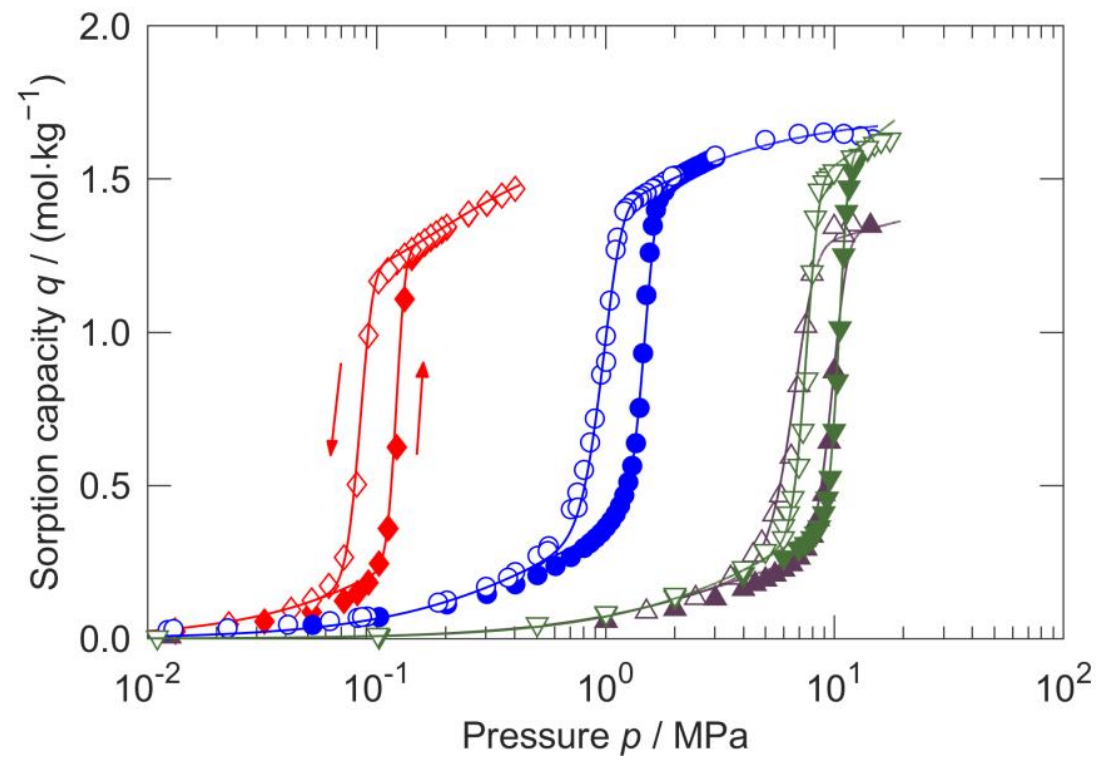

Figure 1. Stepped sorption isotherms of nitrogen $(\Delta \triangle)$, argon $(\nabla \nabla)$, carbon dioxide $(\diamond \diamond)$ and methane $(\bigcirc$ ) on ZIF-7 along the isotherm $T \approx 323 \mathrm{~K}$. Symbols: experimental adsorption (full) and desorption (empty) data; Curves: calculations with the constructed semi-empirical model in this work.

Many further observations of flexible adsorbents have been reported (e.g., carbon dioxide and methane on amino-MIL-53(Al), ${ }^{13}$ and carbon dioxide ${ }^{14}$, ethane and ethylene ${ }^{15}$ on ZIF-7) with a variety of explanations proposed. In many cases, those explanations attributed the increase in capacity to a change in the adsorbent's structure that occurred because of a phase transition. If the main reason for the stepped sorption is the adsorbent's structural phase transition rather than a property specific to gas, inert molecules such as nitrogen and argon should be able to trigger a similar transition and thus exhibit a stepped adsorption isotherm. Since the adsorbent's transition is clearly triggered via interactions of sufficient energy with the adsorbate, potentially the transition would occur at higher pressures for more inert molecules. To this end, sorption isotherm measurements of nitrogen, argon, carbon dioxide, ethane and methane on ZIF-7 at pressures up to 17.0 $\mathrm{MPa}$ over the temperature range (283 to 359 ) $\mathrm{K}$ were carried out. The experimental results reveal stepped sorption isotherms for nitrogen and argon on ZIF-7 with the transition occurring at much higher pressures (5 to $15 \mathrm{MPa})$ than for $\mathrm{CO}_{2}$ and ethane $(<0.4 \mathrm{MPa})$ or methane (1 to 2.5 $\mathrm{MPa}$ ). To describe these stepped hysteretic sorption isotherm data and others like them, a new semi-empirical model was developed. This combines the classical Langmuir equation to describe the Type I sorption behavior before the isotherm's step, with a model that represents the material's structural phase transition in terms of a distribution of pores with varying transition pressures. The new model also describes the hysteresis of the isotherm. 
The remainder of the manuscript is organized as follows. First, we present the conceptual and mathematical framework used to develop the new model. Then we describe the experimental method and present the data together with the results of fits to the new model, discussing possible interpretations of the values obtained for the model parameters.

\section{Model Development}

To correlate the hysteretic stepped sorption isotherm observed in this work and for other systems, a semi-empirical model, as visualized in Figure 2, was constructed by considering the total sorption capacity as the sum of two contributions. The first contribution applies at all pressures and represents the Type I sorption behavior, while the second contribution, $q_{\text {LJMY, applies in certain }}$ pressure range and accounts for the structural phase transition. In this work, we chose the temperature-dependent Langmuir model to represent the Type I sorption behavior:

$$
q_{\text {Langmiur }}=Q_{\mathrm{m}} \cdot \frac{K \cdot \exp (-\Delta H / R \cdot T) \cdot p}{1+K \cdot \exp (-\Delta H / R \cdot T) \cdot p},
$$

where $Q_{\mathrm{m}}$ is the maximum capacity of the Langmuir adsorption, $K$ is the gas-solid affinity coefficient, $\Delta H$ is the enthalpy of adsorption, $T$ is the temperature, $p$ is the pressure, and $R$ is the universal gas constant. For the purposes of describing stepped isotherms, any classical model, such as the $\operatorname{Sips}^{16}$ or Toth ${ }^{17}$ functions, could be used instead of $q_{\text {Langmuir. The total isothermal adsorption }}$ capacity at a given temperature and pressure is calculated by combining the two contributions:

$$
q=q_{\mathrm{Langmiur}}+q_{\mathrm{LJMY}} .
$$

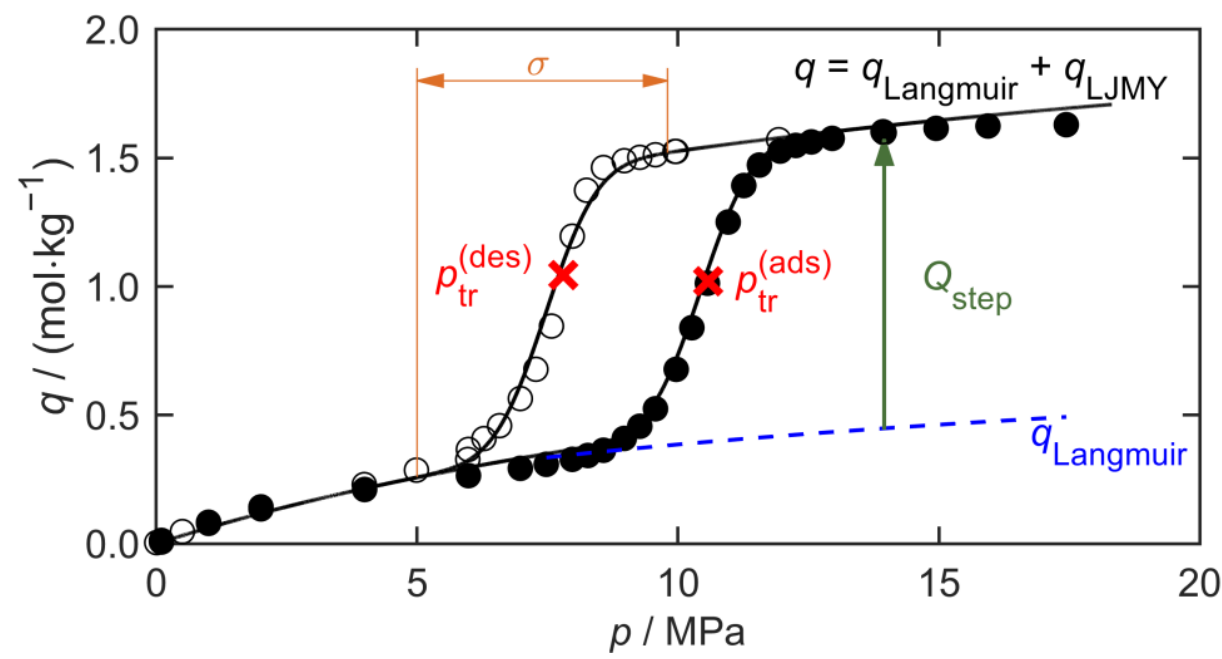

Figure 2. Sorption isotherms of argon on ZIF-7 measured at $T=323 \mathrm{~K}$. $\bullet$, experimental adsorption data; $\odot$, experimental desorption data. Solid curves are fits of Eq. (2), while the dashed curve shows 
an extrapolation of the isotherm's adsorption branch based on a fit of the Langmuir equation to the low pressure data. The meanings of the other symbols are explained in section 2.

The equation for $q_{\text {LJMY }}$ is based on a conceptual model, which assumes that the increased capacity associated with the step is a result of a localized structural phase transition in the adsorbent material (e.g., ZIF-7 in this work), triggered by the presence of an adsorbed phase. Before the coverage of the adsorbed phase is sufficient, the interfacial energy penalty associated with the ZIF-7 surface forces the crystal to minimize its area: this may be called the narrow-pore (np) state. ${ }^{18}$ However, as the amount of adsorbed phase in a local region of the surface increases with gas pressure, the interfacial free energy of the ZIF-7 in that local region decreases. At some threshold value, the reduction in the interfacial free energy is sufficient to drive a localized crystalline phase transition of the ZIF-7, with the resulting structure having a much larger surface area: this may be called the large-pore (lp) state. ${ }^{18}$ The spatial extent of the crystalline transition is limited by the amount of adsorbed phase available to lower the interfacial energy of the ZIF-7 surface. Further increases in gas phase pressure and adsorption allow the ZIF-7 crystal transition to propagate further throughout the material until the sample reaches its maximum possible surface area.

The conceptual model also assumes that the threshold gas pressure required to induce structural transition in the ZIF-7 varies throughout the sample and is described by a Gaussian distribution with a mean and standard deviation of $p_{\text {tr }}$ and $\sigma$, respectively. One possible explanation for this relates to the distribution of pore length scales within the np state. These varying length scales influence the gas pressure, $p_{\mathrm{t}}$, required locally for an amount of adsorption sufficient to trigger the structural transition. Pores in the sample with lower threshold pressures trigger a local np to lp transition earlier along the adsorption isotherm, and the variation between pores is the reason that the entire sample does not undergo the transition at a single pressure. This Gaussian distribution would essentially describe the probability density function, $\operatorname{Pr}\left(p_{t}\right)$, for ZIF-7 pores in the np state to have undergone the structural transition.

$$
\operatorname{Pr}\left(p_{\mathrm{t}}\right)=\frac{1}{\sigma \sqrt{2 \pi}} \exp \left[-\frac{\left(p_{\mathrm{t}}-p_{\mathrm{tr}}\right)^{2}}{2 \sigma^{2}}\right] .
$$

The total adsorbed capacity at a given pressure associated with the ZIF-7 structural transition is determined by integrating this probability density function 


$$
q_{\mathrm{LJMY}}(p)=Q_{\text {step }} \cdot \int_{0}^{p} \operatorname{Pr}\left(p_{\mathrm{t}}\right) d p_{\mathrm{t}}=\frac{1}{2} \cdot\left[1+\operatorname{erf}\left(\frac{p-p_{\mathrm{tr}}}{\sqrt{2} \cdot \sigma}\right)\right] \cdot Q_{\text {step }}
$$

where $Q_{\text {step }}$ is the maximum sorption capacity increase resulting from the sample's structural change. In general, both $p_{\text {tr }}$ and $\sigma$ are temperature-dependent quantities. This can interpreted as reflecting the 'condensation' of the adsorbate molecules from the gas to the adsorbed phase. Moreover, this 'condensation' occurs within the pores of varying length scales in the np state. Accordingly, the functional form used to describe the temperature dependence of $p_{\text {tr }}$ (adsorption $p_{\text {tr }}{ }^{(\text {ads })}$ or desorption $p_{\text {tr }}{ }^{(\mathrm{des})}$ ) is based on the Clausius-Clapeyron equation:

$$
\begin{aligned}
& p_{\mathrm{tr}}^{(\mathrm{ads})}=p_{\mathrm{tr}}^{(\mathrm{des})} \cdot(1+\gamma), \\
& p_{\mathrm{tr}}^{(\mathrm{des})}=p_{\mathrm{tr}, 0}^{(\mathrm{des})} \cdot \exp \left(\frac{\Delta H_{\mathrm{tr}}}{R} \cdot\left(\frac{1}{T_{0}}-\frac{1}{T}\right)\right),
\end{aligned}
$$

where $\Delta H_{\text {tr }}$ is the enthalpy associated with the material's structural transition (np $\left.\leftrightarrow \mathbf{l p}\right)$ which is stimulated by the 'condensation' of the adsorbate molecules, $p_{\mathrm{tr}, 0}{ }^{(\mathrm{des})}$ is the threshold pressure at a reference temperature $T_{0}$ on the desorption pathway, and $\gamma$ is a hysteresis factor related to the interfacial tension and curvature length scale of the adsorbed phase in the pore. Here we consider that the equilibrium capacity measured along the desorption pathway corresponds to the equilibrium state, while that measured along an adsorption pathway reflects the metastable state near the vapor's spinodal. In this work, the reference temperature was taken to be $T_{0}=273.15 \mathrm{~K}$.

A functional form similar to Eq. (6) was used to represent the temperature dependence of the standard distribution $\sigma$ in Eq. (3)

$$
\sigma=\sigma_{0} \cdot \exp \left(\frac{E_{\sigma}}{R} \cdot\left(\frac{1}{T_{0}}-\frac{1}{T}\right)\right)
$$

where $\sigma_{0}$ is the standard deviation at the reference temperature $T_{0}$ and $E_{\sigma}$ is a characteristic energy associated with the variation with temperature of the threshold pressure distribution width. Here we used the same values of $\sigma_{0}$ and $E_{\sigma}$ in the adsorption and desorption branches of the isotherms for the ZIF-7 sample because their temperature dependence was measured to be the same. 
Finally, we consider the maximum increase in sorption capacity, $Q_{\text {step }}$, associated with the step in the isotherm. For simplicity, the conceptual model neglects any variation in $Q_{\text {step }}$ with pressure and consider its temperature dependence to be linear, dominated by the adsorbate's volumetric coefficient of thermal expansion, $\alpha_{\mathrm{v}}$ :

$$
Q_{\text {step }}=Q_{\text {step }, 0} \cdot\left[1-\alpha_{v} \cdot\left(T-T_{0}\right)\right] \text {, }
$$

where $Q_{\text {step, } 0}$ is the maximum increase in stepped sorption capacity at the reference temperature $T_{0}$.

We refer to the conceptual framework used to describe the hysteretic stepped parts of the ZIF-7 sorption isotherm via Eqs (4) to (8) as the LJMY (Li-Jensen-May-Yang) model, and its coupling to the classical Langmuir equation via Eqs (1) and (2) as the LJMY-Langmuir model. This is because it is an adaptation of the LJM (Li-Jensen-May) model ${ }^{19}$ which describes temperatureregulated guest admission and release in microporous materials by considering the thermal energy distribution of the group or specie governing access to the pore. In addition to the three adjustable parameters of the classical Langmuir equation, the LJMY model has a maximum of seven: $p_{\mathrm{tr}, 0}{ }^{\text {(des) }}$, $\sigma_{0}, \gamma, \Delta H_{\mathrm{tr}}, E_{\sigma}, Q_{\mathrm{step}, 0}$ and $\alpha_{v}$. While superficially this is a large number of adjustable parameters, the model does aim to describe both branches of the hysteretic stepped isotherm and the variation with temperature of both the hysteresis and the location of the step. Each of the parameters in the LJMY model can be given a physical interpretation, which helps in the assessment of the best values obtained for each and/or potentially allows them to be fixed in the regression at a value estimated from an independent source. For example, $\alpha_{v}$ can be set to the volumetric coefficient of thermal expansion of the adsorbate in a condensed phase. Furthermore, each of the parameters describes a reasonably orthogonal feature of the adsorption isotherm geometry, and thus robust regression should be possible if data over a sufficient range of pressure and temperature are acquired with high resolution and quantified uncertainties.

\section{Experimental}

\subsection{Synthesis and characterization of ZIF-7}

The ZIF-7 sample was synthesized using the conventional hydrothermal method with a similar procedure to the one described by Arami-Niya et al. ${ }^{10}$ The zinc nitrate hexahydrate (98\%) and benzimidazole were added to a conical flask filled with $150 \mathrm{~mL}$ of dimethylformamide. The mixture solution underwent a 10-minute sonication to ensure all the solid particles initially present were thoroughly dissolved. The solution was then transferred into a $200 \mathrm{~mL}$ Teflon-lined stainlesssteel autoclave, heated to $130{ }^{\circ} \mathrm{C}$ at a rate of $5{ }^{\circ} \mathrm{C}$ per minute, kept at $130{ }^{\circ} \mathrm{C}$ for 48 hours, and 
cooled to room temperature. The mother liquor was centrifuged to separate the ZIF-7 crystals from the bulk of the liquor. The crystals were dried at $90{ }^{\circ} \mathrm{C}$ for 24 hours, and then immersed in methanol at room temperature for 48 hours. After that, the liquor was centrifuged again to separate the bulk of the liquid from the ZIF-7 crystals. The crystals were dried again at $90{ }^{\circ} \mathrm{C}$ for 24 hours. The successful synthesis of ZIF-7 crystals was confirmed by X-ray diffraction (XRD) measurement (Rigaku Ultima X-ray diffractometer with $\mathrm{CuK} \alpha$ radiation at $\lambda=1.5404 \AA$ ). The locations of the peaks in the XRD pattern (see Figure 3) agree well with those reported by Park et al. ${ }^{20}$ The ZIF7 particles are approximately $70 \mu \mathrm{m}$ in length with a cubic morphology; the SEM images of the sample were presented in Arami-Niya et al. ${ }^{10}$

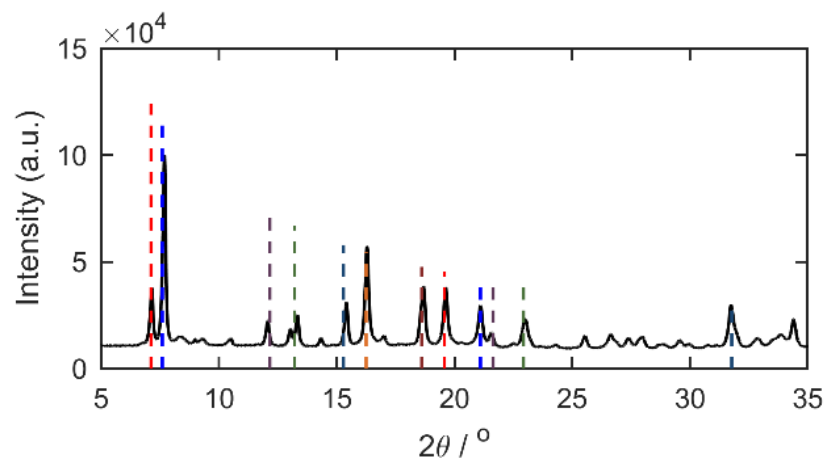

Figure 3. The XRD pattern of the ZIF-7 sample prepared in this study (solid curve) and the characteristic XRD peaks of the ZIF-7 reported by Park et al. (dashed lines).

\subsection{Sorption Capacity Measurement}

Sorption isotherm measurements were conducted with a commercially available gravimetric sorption analyzer (Rubotherm, Germany, and since 2016, TA instrument, USA). This type of instrument has been widely used for accurate sorption measurements, ${ }^{10,21-24}$ and with comprehensive improvements, it is capable to measure sorption capacity even of non-porous material. ${ }^{25}$ Detailed information about the measurement principle can be found from literature, ${ }^{26-}$

${ }^{27}$ here, we only summarize the key details of our system. The sorption analyzer can operate over the temperature range (283 to 423 ) $\mathrm{K}$ at pressures up to $35 \mathrm{MPa}$. The temperature of the gas sample was measured with a calibrated $100 \Omega$ platinum resistance thermometer monitored by a digital multimeter (Millik Precision Thermometer, Isotech, UK). The expanded uncertainty $(k=2)$ of the temperature-measurement chain was estimated to be $0.30 \mathrm{~K}$ over the investigated temperature range. The pressure was measured with a vibrating quartz-crystal-type transmitter (range up to 41.3 MPa, 46K-HH, Paroscientific, USA) with an uncertainty of $0.01 \%$ of full scale, i.e., $4.1 \mathrm{kPa}$. 
The weighing of the ZIF-7 sample was conducted with an magnetic-suspension balance, which includes an analytical balance $\left(1 \mu \mathrm{g}\right.$ resolution) and a magnetic-suspension coupling ${ }^{26}$.

Before any sorption measurements, the ZIF-7 sample was activated inside the measuring cell of the gravimetric analyzer at a temperature of approximately $180{ }^{\circ} \mathrm{C}$ and a pressure lower than 1.0 $\mathrm{Pa}$ (achieved with a rotary vane pump provided by Vacuubrand, Germany, type: RZ 6) overnight. The mass of the sample ( $m \approx 0.7513 \mathrm{~g}$ ) was determined after the activation, while the sample volume $\left(V \approx 0.3573 \mathrm{~cm}^{3}\right)$ was determined by measuring the buoyancy force produced by pure helium at $282.76 \mathrm{~K}$ in the pressure range (2 to 8 ) $\mathrm{MPa}$ under the assumption that helium was not adsorbed on the sample. The isothermal measurements were conducted first with increasing pressure steps and then with decreasing pressure steps. An equilibration time of 40 to 60 minutes was allowed after a change in pressure, and the measurement at a given pressure generally lasted 20 to 40 minutes. For some temperatures, a second isotherm consisting only of decreasing pressure steps and some with extra pressure points was carried out the check the measurement repeatability.

The adsorbate gases were all provided by Coregas, Australia with the following stated molefraction purities: 0.9999 for ethane, 0.99995 for carbon dioxide and methane, and 0.99999 for nitrogen, argon and helium. They were used as received from the supplier without further gas analysis or purification. Detailed information regarding the gas impurities is listed in Table 1.

Table 1. Gas sample information

\begin{tabular}{llll}
\hline Chemical name & Source & Purity/mole fraction & Purification method \\
\hline Methane & Coregas & $0.99995^{a}$ & none \\
Nitrogen & Coregas & $0.99999^{b}$ & none \\
Argon & Coregas & $0.99999^{c}$ & none \\
Carbon dioxide & Coregas & $0.99995^{d}$ & none \\
Ethane & Coregas & $0.9999^{e}$ & none \\
Helium & Coregas & $0.99999^{f}$ & none \\
\hline
\end{tabular}

${ }^{a}$ Impurities (stated by supplier): $x\left(\mathrm{H}_{2} \mathrm{O}\right) \leq 5 \times 10^{-6}, x\left(\mathrm{O}_{2}\right) \leq 4 \times 10^{-6}, x\left(\right.$ other $\left.\mathrm{C}_{\mathrm{m}} \mathrm{H}_{\mathrm{n}}\right) \leq 20 \times 10^{-6}, x\left(\mathrm{~N}_{2}\right)$ $\leq 20 \times 10^{-6}, x\left(\mathrm{H}_{2}\right) \leq 1 \times 10^{-6}$, where $x$ denotes mole fraction.

${ }^{b}$ Impurities (stated by supplier): $x\left(\mathrm{H}_{2} \mathrm{O}\right) \leq 5.0 \times 10^{-6}, x\left(\mathrm{O}_{2}\right) \leq 3.0 \times 10^{-6}$

${ }^{c}$ Impurities (stated by supplier): $x\left(\mathrm{H}_{2} \mathrm{O}\right) \leq 1.5 \times 10^{-6}, x\left(\mathrm{O}_{2}\right) \leq 1.0 \times 10^{-6}, x\left(\mathrm{C}_{\mathrm{m}} \mathrm{H}_{\mathrm{n}}\right) \leq 0.5 \times 10^{-6}, x\left(\mathrm{CO}_{2}\right)$ $\leq 0.5 \times 10^{-6}, x\left(\mathrm{~N}_{2}\right) \leq 5.0 \times 10^{-6}$.

${ }^{d}$ Impurities (stated by supplier): $x\left(\mathrm{H}_{2} \mathrm{O}\right) \leq 7 \times 10^{-6}, x\left(\mathrm{O}_{2}\right) \leq 10 \times 10^{-6}, x\left(\mathrm{C}_{\mathrm{m}} \mathrm{H}_{\mathrm{n}}\right) \leq 5 \times 10^{-6}, x(\mathrm{CO}) \leq$ $7 \times 10^{-6}$.

${ }^{e}$ The main impurities are the other hydrocarbons.

${ }^{f}$ Impurities (stated by supplier): $x\left(\mathrm{H}_{2} \mathrm{O}\right) \leq 3.0 \times 10^{-6}, x\left(\mathrm{O}_{2}\right) \leq 2.0 \times 10^{-6}, x\left(\mathrm{C}_{\mathrm{m}} \mathrm{H}_{\mathrm{n}}\right) \leq 0.5 \times 10^{-6},\left(\mathrm{~N}_{2}\right) \leq$ $8.0 \times 10^{-6}$. 


\subsection{Data analysis and uncertainty}

The absolute adsorbed mass $m_{\text {sorp }}$ on the ZIF-7 sample was calculated with:

$$
m_{\text {sorp }}=\left[m_{\text {fluid }}^{*}-m_{\text {vac }}^{*}+\rho_{\text {fluid }} V_{\mathrm{CP}}\right] \cdot \frac{\rho_{\text {sorp }}}{\rho_{\text {sorp }}-\rho_{\text {fluid }}} .
$$

Here $m_{\text {fluid }}^{*}=\left(W_{1}-W_{0}\right)_{\text {fluid }} / \alpha$ and $m_{\text {vac }}^{*}=\left(W_{1}-W_{0}\right)_{\text {vac }} / \alpha$, where $W_{0}$ and $W_{1}$ are the readings of the magnetic-suspension balance at the positions ZP (tare or zero position) and MP (measuring position). From positions ZP to MP, the magnetic suspension coupling is changed so that the sample container holding the ZIF-7 is lifted off its stop and weighed by the microbalance. The term $\alpha=\left(1-\rho_{\text {air }} / \rho_{\text {calib }}\right)^{-1} \approx 1.000150$ is the balance calibration factor, with $\rho_{\text {air }}$ being the mass density of the laboratory air and $\rho_{\text {calib }}$ being the density of the calibration mass used by the balance. The subscripts 'vac' and 'fluid' denote that the measurements were conducted with the measuring cell evacuated or filled with fluid, respectively. In Eq. (9), $\rho_{\text {fluid }}$ is the density of the fluid, which was calculated at the measured temperature and pressure using each the reference equations of state (EOS) for carbon dioxide ${ }^{28}$, ethane ${ }^{29}$, nitrogen ${ }^{30}$, methane ${ }^{31}$ or $\operatorname{argon}^{32}$ as implemented in the software package REFPROP $10.0 ;{ }^{33} V_{\mathrm{CP}}$ is the combined volume of the ZIF-7 sample and the container and $\rho_{\text {sorp }}$ is the density of the adsorbate. The value $\rho_{\text {sorp }}$ was estimated to be the saturated liquid density at the triple point for carbon dioxide and at the standard boiling point pressure for the other five fluids. The adsorption capacity $q$ of ZIF-7 is then determined by

$$
q=\left(m_{\text {sorp }} / M_{\text {fluid }}\right) / m,
$$

where $M_{\text {fluid }}$ is the molar mass of the adsorbate and $m$ is the mass of the ZIF-7 sample.

In Eq. (9), the term $\rho_{\text {fluid }} \cdot V_{\mathrm{CP}}$ accounts for the buoyancy force on the ZIF-7 sample and its container, and the term $\rho_{\text {sorp }} /\left(\rho_{\text {sorp }}-\rho_{\text {fluid }}\right)$ is a correction factor applied to account for the increase in buoyancy force associated with the volume occupied by the adsorbed phase. As discussed by Yang et al. ${ }^{27}$ the influence of the systematic force transmission error ${ }^{34}$ on the adsorption measurement of porous material is negligibly small and, therefore, was not considered in this work.

The combined uncertainty of the adsorbed mass measurement, $u_{\mathrm{C}}\left(m_{\mathrm{sorp}}\right)$, can be determined according to the "Guide to the Expression of Uncertainty in Measurement" 35 by applying error propagation considerations to Eq. (9): 


$$
\begin{aligned}
u_{\mathrm{C}}\left(m_{\text {sorp }}\right)^{2}= & \left\{u\left(m_{\mathrm{CP}, \text { fluid }}^{*}\right)^{2}+u\left(m_{\mathrm{CP}, \text { vac }}^{*}\right)^{2}+\left[V_{\mathrm{CP}} \cdot u_{\mathrm{C}}\left(\rho_{\text {fluid }}\right)\right]^{2}+\left[\rho_{\text {fluid }} \cdot u\left(V_{\mathrm{CP}}\right)\right]^{2}\right\} \\
& \cdot\left(1-\frac{\rho_{\text {fluid }}}{\rho_{\text {sorp }}}\right)^{-2}+\frac{\left(m_{\text {sorp }}\right)^{2}}{\left(\rho_{\text {sorp }}-\rho_{\text {fluid }}\right)} \cdot\left[u\left(\rho_{\text {fluid }}\right)+\frac{\rho_{\text {fluid }}}{\rho_{\text {sorp }}} \cdot u\left(\rho_{\text {sorp }}\right)\right]^{2},
\end{aligned}
$$

where the combined uncertainty in density $u_{\mathrm{C}}\left(\rho_{\text {fluid }}\right)$ was calculated by:

$$
u_{\mathrm{C}}\left(\rho_{\text {fluid }}\right)=\left[u_{\mathrm{EOS}}(\rho)^{2}+\left(\left(\frac{\partial \rho}{\partial T}\right)_{p} \cdot u(T)\right)^{2}+\left(\left(\frac{\partial \rho}{\partial p}\right)_{T} \cdot u(p)\right)^{2}\right]^{0.5}
$$

In equation (12), $u_{\operatorname{EOS}}(\rho)$ is the uncertainty in density of the reference EOS for each adsorbate, and the partial derivatives were also evaluated numerically using this reference EOS. Application of error propagation to Eq. (10), allows the relative combined uncertainty of the porous material's adsorption capacity $u_{\mathrm{C}}(q) / q$ to be calculated with

$$
\left[\frac{u_{\mathrm{C}}(q)}{q}\right]^{2}=\left[\frac{u_{\mathrm{C}}\left(m_{\text {sorp }}\right)}{m_{\text {sorp }}}\right]^{2}+\left[\frac{u(m)}{m}\right]^{2},
$$

where the uncertainty of the molar mass was negligibly small.

Combining the various sources of measurement uncertainty including those associated with temperature, pressure, balance weighing, mass and volume of the ZIF-7 sample, the combined expanded uncertainty $(k=2)$ of the sorption capacity $U_{\mathrm{C}}(q)$ was estimated to be from 0.006 $\mathrm{mol} \cdot \mathrm{kg}^{-1}$ at the lowest pressures up to $0.16 \mathrm{~mol} \cdot \mathrm{kg}^{-1}$ at the highest pressures. The combined expanded uncertainty of each experimental point is listed in Tables S1-S5 in the Supplementary Information. In general, the major uncertainty contributions in the low, medium and high pressure ranges are the pressure measurement, the balance weighing, and the volume of the ZIF-7 sample, respectively. An example for the uncertainty budget for the relative uncertainty $U_{\mathrm{C}}(q) / q$ is summarized in Table 2 for the measurement of methane at $T=283.18 \mathrm{~K}$ and $p=0.2028 \mathrm{MPa}$. Only uncertainties associated with measurements were considered, whereas those associated with the impurities in the gas sample (negligibly small because of the high gas purity) and in the ZIF-7 sample were not. The influence of the impurities in the ZIF-7 sample is difficult to quantify. The purity of the ZIF-7 sample would not be better than $98 \%$ because the purity of one of the main ingredients (zinc nitrate hexahydrate) is only $98 \%$.

Table 2. Uncertainty budget for the sorption capacity $q$ of ZIF-7. As an example, the measurement of methane at temperature $283.18 \mathrm{~K}$ and pressure $0.2028 \mathrm{MPa}$ was taken. 


\begin{tabular}{|c|c|c|}
\hline Sources $^{[\mathrm{a}]}$ & $\begin{array}{l}\text { Uncertainty } \\
U(k=2)\end{array}$ & $\begin{array}{l}\text { Contribution } \\
\text { to } U_{\mathrm{C}}(q) / q\end{array}$ \\
\hline Temperature $U(T)$ & & $(0.001)$ \\
\hline Pres & $2 \mathrm{MPa}$ & $(0.023)$ \\
\hline Den & & 00) \\
\hline Combinec & $0.015 \mathrm{~kg} \cdot 1$ & 0.023 \\
\hline$\left.n_{\text {vac }}^{*}\right)$ & $90 \mu \mathrm{g}$ & 0.031 \\
\hline Weighing va & $90 \mu \mathrm{g}$ & 0.031 \\
\hline Volume & $0.014 \mathrm{~cm}^{3}$ & 0.007 \\
\hline Dens & $10 \%$ & 0.000 \\
\hline Mass of $\mathrm{t}$ & $0.20 \mathrm{mg}$ & 0.000 \\
\hline \multicolumn{2}{|c|}{ Relative combined expanded uncertainty $(k=2)$ in sorption capacity $U_{\mathrm{C}}(q) / q$} & 0.050 \\
\hline \multicolumn{3}{|c|}{ 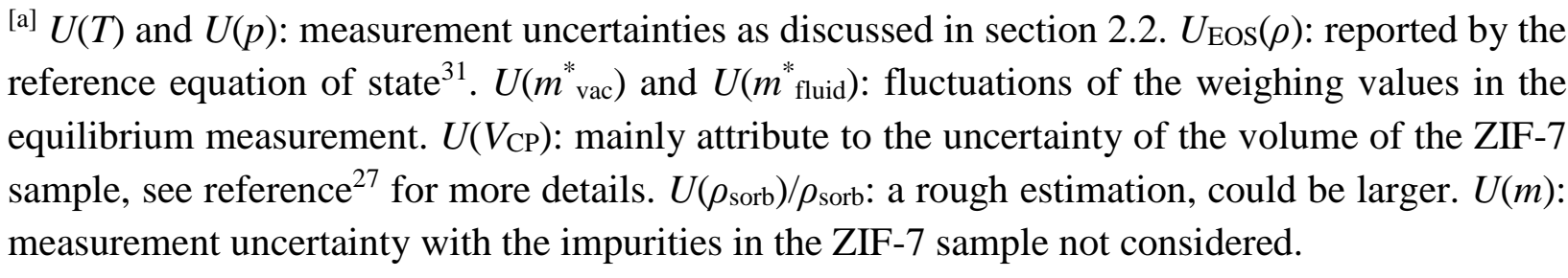 } \\
\hline
\end{tabular}

\section{Measurement results}

The $(T, p, q)$ data measured at temperatures from 283 to $359 \mathrm{~K}$ and pressures up to $17.0 \mathrm{MPa}$ are listed for each adsorbate in Tables S1-S5 of Supplementary Information. The absolute sorption isotherm data together with the resulting fits of the LJMY-Langmuir model are shown in Figure 4 for nitrogen and argon, and in Figure 5 for carbon dioxide, ethane and methane; while the excess sorption isotherms are illustrated in Figures S1 and S2 in Supplementary Information. The repeated measurements generally agree with each other within the reported uncertainty. While hysteretic stepped sorption isotherms have been reported previously for these last three adsorbates on ZIF-7, they have not been reported for the more inert nitrogen and argon because of the much high pressures required to induce the structural transition. For each adsorbate, the transition pressure $p_{\text {tr }}$ and the transition width, $\sigma$, increase with temperature, which reflects the founding assumptions used to develop the LJMY conceptual model. Although no significant difference among these five gases was observed in terms of ultimate sorption capacity, the transition pressures $p_{\text {tr }}$ at the same temperature are significantly different. Potentially, a sophisticated pressure swing adsorption process operating around one or more of the transition pressures could therefore be designed using ZIF-7 to separate mixtures of these gases. 

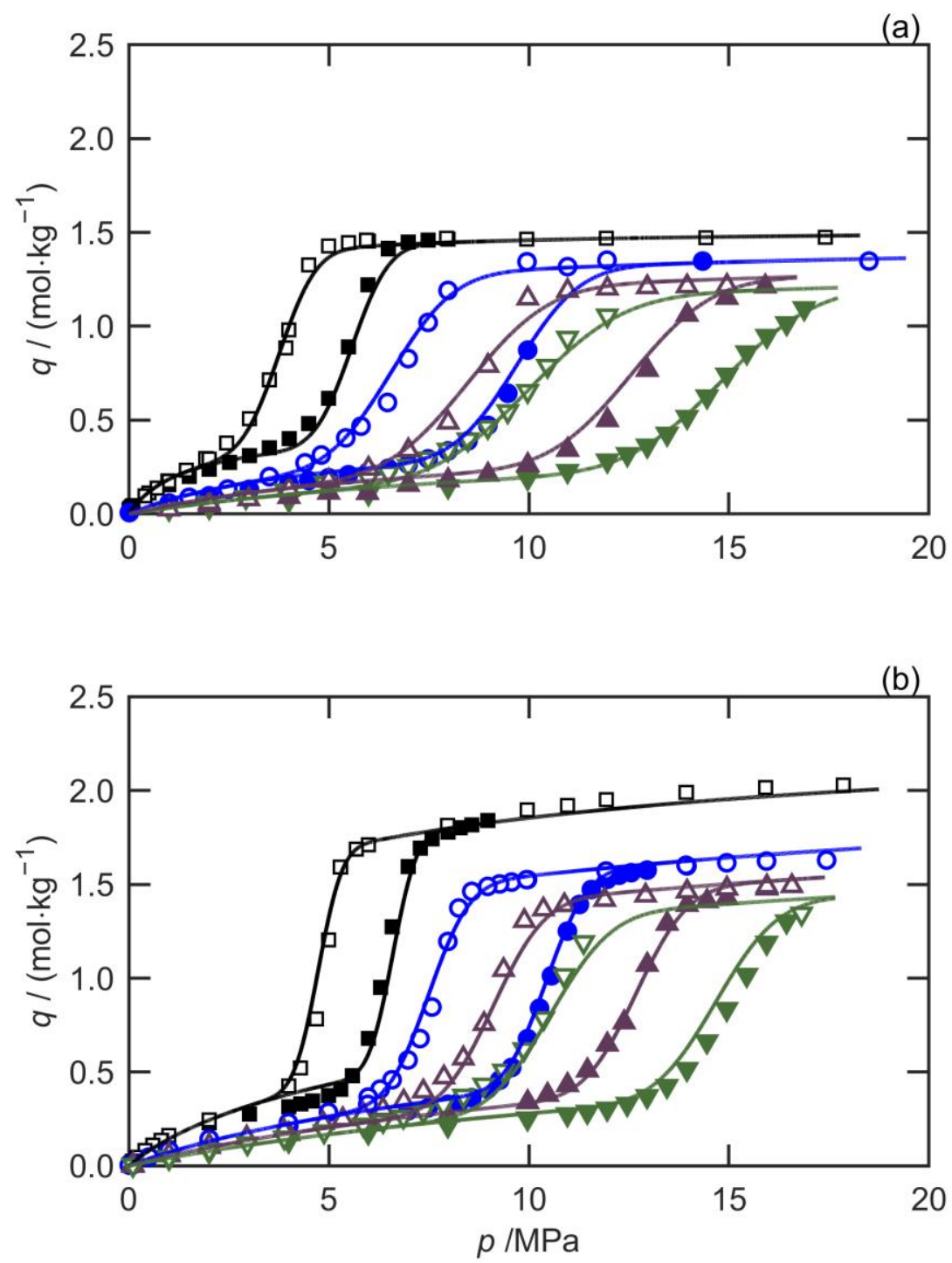

Figure 4. Sorption behavior of ZIF-7 for (a) $\mathrm{N}_{2}$, (b) Ar. $\square \square, T=283 \mathrm{~K}, \bigcirc \bigcirc, T=322 \mathrm{~K}, \boldsymbol{\Delta} \triangle$, $T=341 \mathrm{~K} . \nabla \nabla, T=359 \mathrm{~K}$; full: adsorption, empty: desorption. The solid curves are the fits of the LJMY- Langmuir model to the experimental data. 
(a)

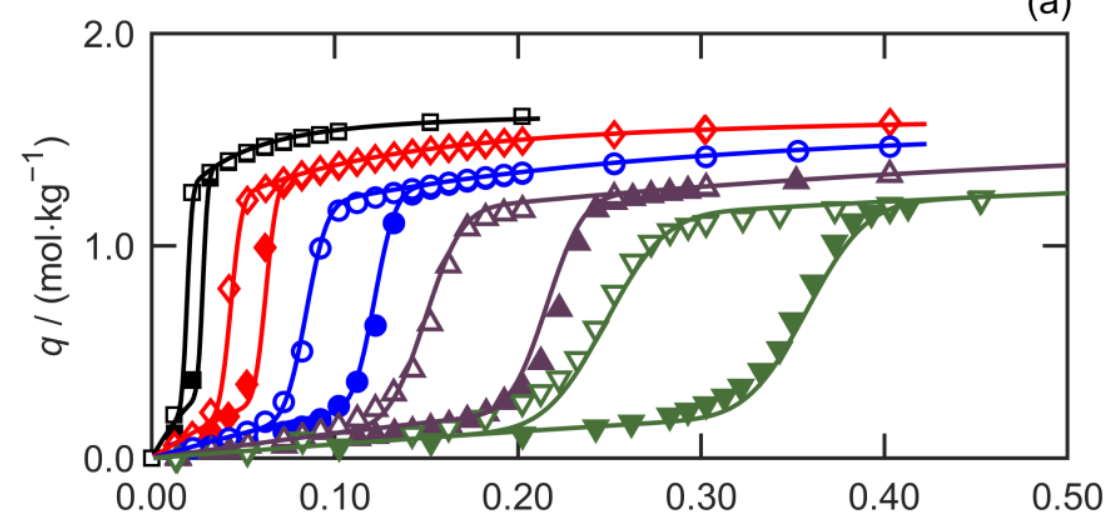

(b)

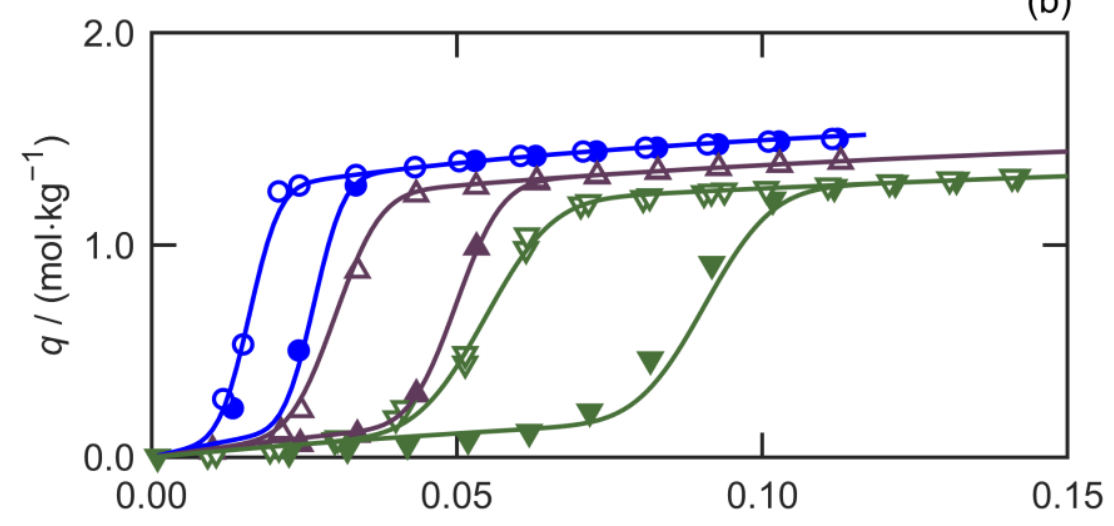

(c)



Figure 5. Sorption behaviors of ZIF-7 for (a) $\mathrm{CO}_{2}$, (b) $\mathrm{C}_{2} \mathrm{H}_{6}$, (c) $\mathrm{CH}_{4} . \quad \square, T=283 \mathrm{~K}, \diamond \diamond, T$ $=303 \mathrm{~K}, \bigcirc \bigcirc, T=322 \mathrm{~K}, \Delta \triangle, T=341 \mathrm{~K} . \nabla \nabla, T=359 \mathrm{~K}$; full: adsorption, empty: desorption. The solid curves are the fits of the LJMY-Langmuir model to the experimental data. 
The experimental $(T, p, q)$ data for carbon dioxide, methane and nitrogen at pressures lower than $5.0 \mathrm{MPa}$ at $T=323 \mathrm{~K}$ are compared with data of Arami-Niya et al. ${ }^{10}$ in Figure 6. The sorption capacities measured in this work for ZIF-7 are generally slightly larger than those observed by Arami-Niya et al. ${ }^{10}$ in the low pressure range, and somewhat smaller in the higher pressure range, with the difference being larger than the estimated uncertainty of the present measurements. Considering that the ZIF-7 samples used in this work and by Arami-Niya et al. ${ }^{10}$ were activated at slightly different conditions, the adsorption measurements were conducted with different apparatus, and the raw data were analyzed by different methods, the variance in the measured adsorption capacity is plausible. van den Bergh et al. ${ }^{36}$ conducted ZIF-7 sorption measurements for carbon dioxide at $T=298 \mathrm{~K}$ and reported a hysteresis magnitude, $\delta p_{\text {tr }} \equiv p_{\text {tr }}{ }^{(\text {ads })}-p_{\text {tr }}{ }^{(\mathrm{des})}$ of approximately $0.0022 \mathrm{MPa}$. In this work, the value of $\delta p_{\text {tr }}$ measured for carbon dioxide at $298 \mathrm{~K}$ was $0.0014 \mathrm{MPa}$.

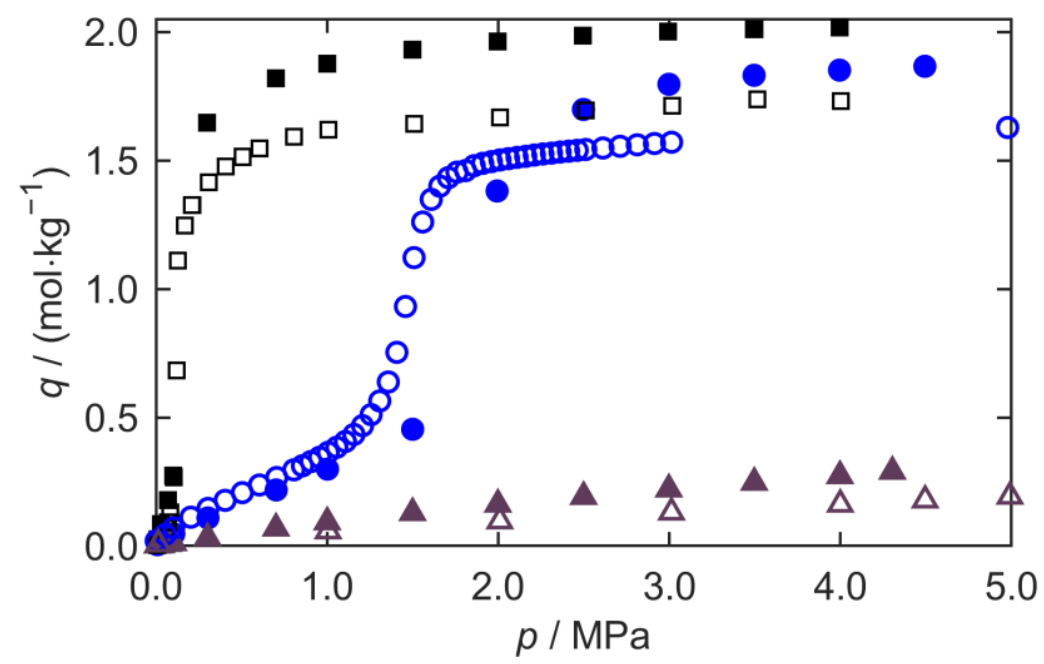

Figure 6. Adsorption isotherms of $\mathrm{CO}_{2}(\square \square), \mathrm{CH}_{4}(\bigcirc \bigcirc)$, and $\mathrm{N}_{2}(\Delta \triangle)$ on ZIF-7 at $T \approx 323 \mathrm{~K}$. Full symbols: Arami-Niya et al. ${ }^{10}$; empty symbols: this work. The error bars for the standard measurement uncertainty of this work are within the vertical size of the symbols.

\section{Discussion}

The LJMY-Langmuir model has a maximum of ten adjustable parameters; however, for the ranges of temperature, pressure and adsorbate considered in this work only nine were needed to correlate the ZIF-7 sorption data acquired here. Initially, the experimental $(p, T, q)$ data were regressed to equation (2) with all ten parameters in the LJMY-Langmuir model adjusted for each fluid. The relative standard uncertainty of all parameters is generally less than $10 \%$ except for $K$ and the volume coefficient of thermal expansion of the adsorbate $\alpha_{v}$. The best-fit values of $\alpha_{v}$ obtained for each gas in this first regression are shown in Figure 7 together with their statistical uncertainties. 
Each value of $\alpha_{v}$ obtained by fitting is comparable with the volume coefficient of thermal expansion of the adsorbate substance at the triple point temperature in either the solid phase (estimated from the literature: nitrogen ${ }^{37}$, argon ${ }^{38}$, carbon dioxide ${ }^{39}$, ethane ${ }^{40}$ and methane ${ }^{41}$ ) and/or the liquid phase (estimated with REFPROP $10.0^{33}$ ). Furthermore, for all the fluids a value of $0.0013 \mathrm{~K}^{-1}$ was within the uncertainty bounds of each best-fit value of $\alpha_{v}$. Therefore a second correlation was carried out with the value $\alpha_{\nu}$ constrained to be $0.0013 \mathrm{~K}^{-1}$.

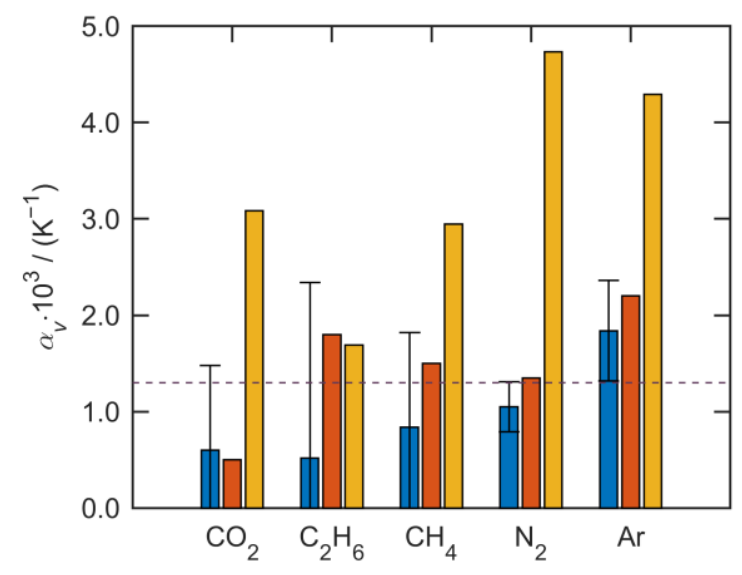

Figure 7. The correlated volumetric coefficient of thermal expansion $\alpha_{\nu}$ of the adsorbate on ZIF7 ( $\square$ ) with its expanded uncertainty $(k=2)$ and that of the adsorbate substance at the triple point temperature in the solid phase ( $\square$ ) and liquid phase ( $\square$ ). The dashed line depicts the constant $\alpha_{v}=$ $0.0013 \mathrm{~K}^{-1}$.

The best-fit results for the remaining nine parameters are listed in Table 3 together with the standard uncertainty of each parameter and the fit's root-mean-square (RMS) deviation from the experimental data. The RMS deviation is in the same order as the reported uncertainty of the experimental data. The relative standard uncertainty of all parameters is generally less than $10 \%$ except for $K$ for which it is approximately $30 \%$. For the five adsorbate gases considered, $Q_{\text {step }, 0}$ is remarkably constant, ranging from (1.03 to 1.24$) \mathrm{mol} \cdot \mathrm{kg}^{-1}$, even though the location of the step in the isotherm at the reference temperature, $p_{\mathrm{tr}, 0}{ }^{\text {(des) }}$, varies by a factor of about 2000 . This indicates that the change in the sorption capacity is associated with the increase in ZIF-7 surface area caused by the structural transition with little variation due to the affinity of the gas for the adsorption sites made available. 
Table 3. Best-fit LJMY-Langmuir parameters and their standard statistical uncertainties $u$.

\begin{tabular}{|c|c|c|c|c|c|c|c|c|c|c|}
\hline \multirow[b]{2}{*}{ Parameters } & \multicolumn{2}{|c|}{ Carbon dioxide } & \multicolumn{2}{|c|}{ Ethane } & \multicolumn{2}{|c|}{ Methane } & \multicolumn{2}{|c|}{ Nitrogen } & \multicolumn{2}{|c|}{ Argon } \\
\hline & Value & $u$ & Value & $u$ & Value & $u$ & Value & $u$ & Value & $u$ \\
\hline$Q_{\mathrm{m}} /\left(\mathrm{mol} \cdot \mathrm{kg}^{-1}\right)$ & 0.695 & 0.034 & 0.656 & 0.013 & 0.679 & 0.014 & 0.475 & 0.038 & 1.402 & 0.114 \\
\hline $10^{5} \mathrm{~K} / \mathrm{MPa}^{-1}$ & 3.21 & 1.07 & 26.59 & 11.32 & 57.48 & 11.04 & 1.78 & 0.93 & 14.13 & 3.27 \\
\hline$\Delta H /\left(\mathrm{kJ} \cdot \mathrm{mol}^{-1}\right)$ & -31.59 & 0.98 & -28.69 & 1.21 & -20.32 & 0.52 & -24.61 & 1.57 & -15.41 & 0.75 \\
\hline$Q_{\text {step }, 0} /\left(\mathrm{mol} \cdot \mathrm{kg}^{-1}\right)$ & 1.087 & 0.014 & 1.219 & 0.015 & 1.110 & 0.010 & 1.084 & 0.021 & 1.168 & 0.019 \\
\hline$\alpha_{\nu}^{[\mathrm{a}]} / \mathrm{K}^{-1}$ & 0.0013 & & 0.0013 & & 0.0013 & & 0.0013 & & 0.0013 & \\
\hline$p_{\mathrm{tr}, 0}{ }^{(\mathrm{des})} / \mathrm{MPa}$ & 0.0125 & 0.0001 & 0.0019 & 0.0000 & 0.3735 & 0.0021 & 3.1872 & 0.0257 & 4.0978 & 0.0262 \\
\hline$\gamma$ & 0.4419 & 0.0066 & 0.6577 & 0.0093 & 0.5263 & 0.0060 & 0.4781 & 0.0088 & 0.4006 & 0.0061 \\
\hline$\Delta H_{\mathrm{tr}} /\left(\mathrm{kJ} \cdot \mathrm{mol}^{-1}\right)$ & 28.33 & 0.11 & 31.74 & 0.22 & 13.76 & 0.07 & 10.69 & 0.10 & 8.87 & 0.07 \\
\hline$\sigma_{0} /(\mathrm{MPa})$ & 0.0018 & 0.0002 & 0.0009 & 0.0001 & 0.0593 & 0.0027 & 0.584 & 0.041 & 0.349 & 0.031 \\
\hline$E_{\sigma} /\left(\mathrm{kJ} \cdot \mathrm{mol}^{-1}\right)$ & 25.57 & 1.32 & 21.85 & 1.80 & 14.46 & 0.58 & 10.50 & 0.78 & 11.64 & 1.06 \\
\hline $\mathrm{RMS} /\left(\mathrm{mol} \cdot \mathrm{kg}^{-1}\right)$ & 0.042 & & 0.024 & & 0.030 & & 0.038 & & 0.052 & \\
\hline
\end{tabular}

${ }^{[\mathrm{a}]} \alpha_{v}$ was set as a constant. 
The parameters $p_{\text {tr }}{ }^{\text {(des) }}, \sigma$ and $Q_{\text {step }}$ in Eq. (4) are related to temperature according to Eqs. (6), (7) and (8), respectively. For ZIF-7 and these adsorbate gases over the temperature range considered, we initially set $\gamma$ to be independent of temperature. To test these relations, the values of $Q_{\text {step }}, p_{\text {tr }}{ }^{\text {(des) }}$, $\sigma$ and $\gamma$ at each temperature were determined by independently regressing each experimental isotherm branch (adsorption and desorption) to Eqs. (1) (2) (4) and (5) by treating them as adjustable parameters. The results obtained at each temperature are depicted in Figure 8: excellent linear relations were observed for $\ln \left(p_{\text {tr }}{ }^{(\mathrm{des})} / p_{\mathrm{tr}, 0}{ }^{(\mathrm{des})}\right) v s 1 / T$ as well as $\ln \left(\sigma / \sigma_{0}\right) v s 1 / T$, while a modest correlation was found between $Q_{\text {step }}-Q_{\text {step }, 0}$ and $T$. The value of $\gamma$ appears to have a weak temperature dependence for methane and argon but no correlation with temperature is evident for other three gases. Values of $p_{\text {tr }}^{\text {(des) }}, \sigma$ and $Q_{\text {step }}$ calculated with Eqs. (6), (7) and (8) respectively, using the best-fit parameters listed in Table 3 are also plotted in Figure 8 as solid curves. These calculations agree well with the values of $Q_{\text {step }}, p_{\text {tr }}{ }^{(\mathrm{des})}$ and $\sigma$ obtained separately for each isotherm, indicating the temperature dependence of the LJMY model is appropriate. For $\mathrm{CO}_{2}$, the values of $p_{\text {tr }}{ }^{\text {des) }}$ calculated at each temperature are consistent with those reported by Rahman et al. ${ }^{42}$ who conducted ZIF-7 capacity measurements with a volumetric technique to much lower temperatures, as shown in Figure 9. 

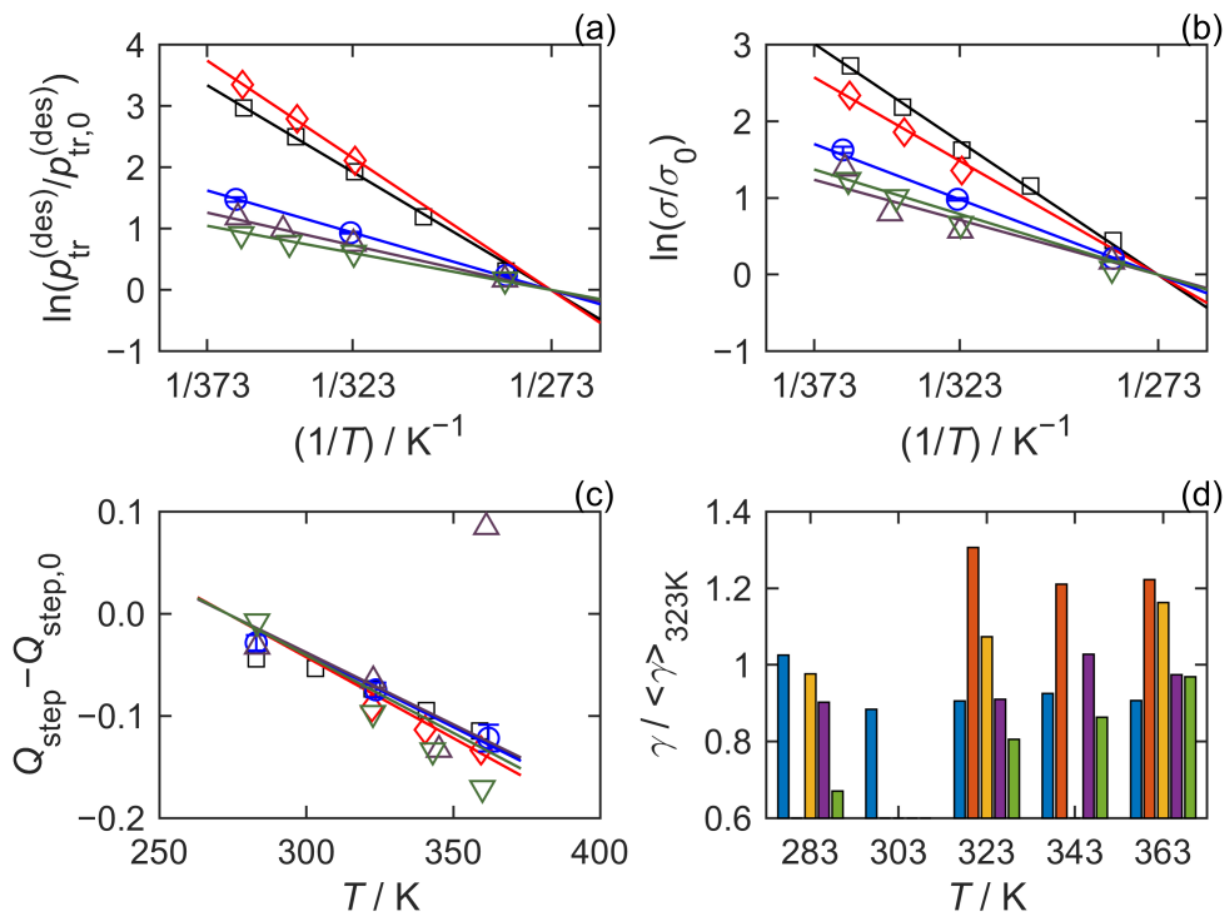

Figure 8. The relation of the parameters $Q_{\text {step }}, \gamma, p_{\text {tr }}{ }^{(\mathrm{des})}$ and $\sigma$ with the temperature $T$. The symbols ( $\square \mathrm{CO}_{2}, \diamond \mathrm{C}_{2} \mathrm{H}_{6}, \circ \mathrm{CH}_{4}, \triangle \mathrm{N}_{2}, \nabla$ Ar in subfigures a b c, and $\square \mathrm{CO}_{2}, \square \mathrm{C}_{2} \mathrm{H}_{6}, \square \mathrm{CH}_{4}, \square \mathrm{N}_{2}, \square \mathrm{Ar}$ in subfigure d) were obtained from independent fits of each isotherm to Eqs. (1) (2) (4) and (5) with $Q_{\text {step }}, \gamma, p_{\text {tr }}{ }^{\text {(des) }}$ and $\sigma$ as adjustable parameters. Solid lines for $p_{\text {tr }}{ }^{\left({ }^{(d e s)}\right.}, \sigma$ and $Q_{\text {step were calculated }}$ with Eqs. (6), (7) and (8), respectively, using the best-fit parameters listed in Table 3. $\langle\gamma\rangle_{323 \mathrm{~K}}$ is the average value over all gases at $323 \mathrm{~K}$. The subscript 0 denotes the value at the reference temperature $T_{0}=273.15 \mathrm{~K}$. 

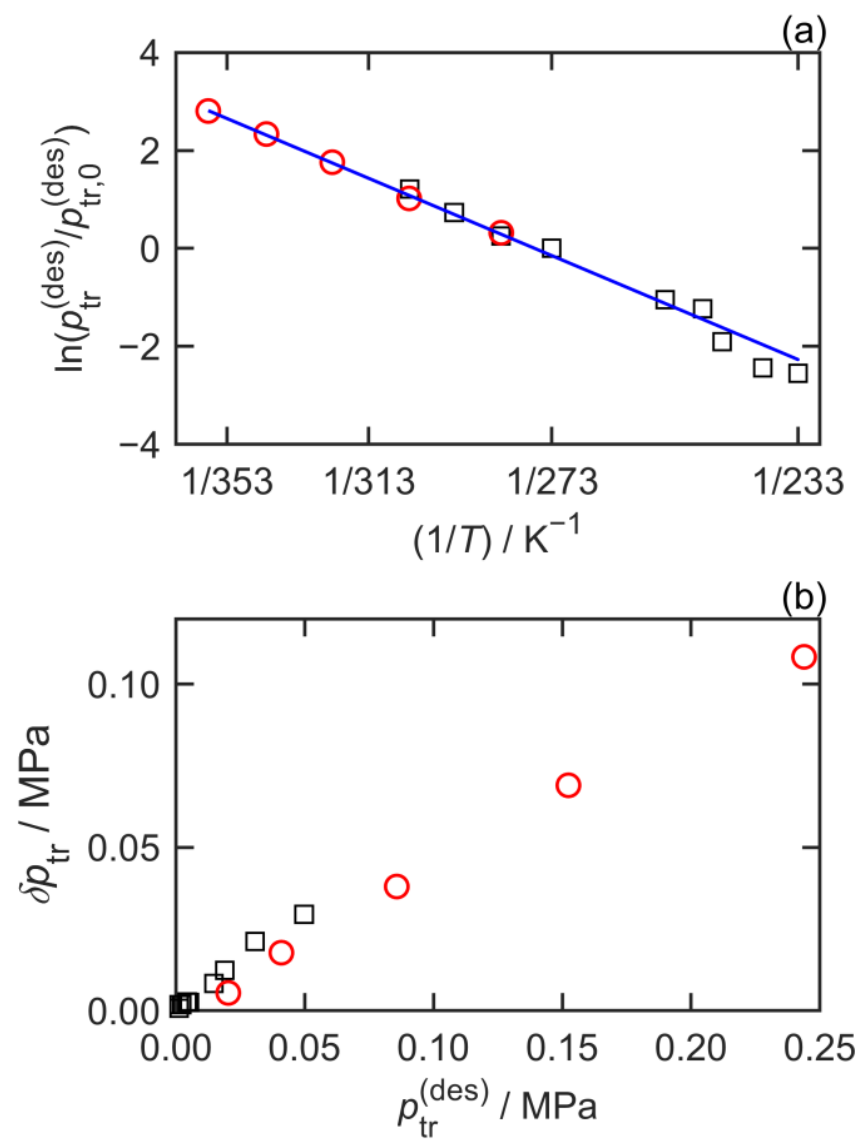

Figure 9. (a) Variation of desorption transition pressure $p_{\mathrm{tr}}{ }^{(\mathrm{des})}$ with temperature $T$ for $\mathrm{CO}_{2}$ on $\mathrm{ZIF}$ 7. (b) Asymptotic dependence of $\delta p_{\text {tr }}=p_{\text {tr }}{ }^{(\text {ads })}-p_{\text {tr }}{ }^{\text {(des) }}$ with $p_{\text {tr }}{ }^{\text {(des) }}$. $\circ$, this work; $\square$, Rahman et al..$^{42}$. The blue line in panel (a) is a linear fit to the experimental data measured in this work and the subscript 0 denotes the value at the reference temperature $T_{0}=273.15 \mathrm{~K}$.

For ZIF-7, several parameters in the LJMY model, namely $\Delta H_{\mathrm{tr}}, Q_{\mathrm{step}, 0}, \sigma_{0}$, and $E_{\sigma}$ were initially assumed to exhibit no hysteresis (i.e. have the same values along the adsorption and desorption branches). To test these assumptions further, sorption data from each branch of each isotherm were regressed separately to the LJMY-Langmuir model without considering the hysteresis factor $\gamma$. The resulting best-fit values of each isotherm branch parameter are shown for each adsorbate in Figure 10. In general, the differences in the parameters obtained on each branch are consistent with each other within their expanded $(k=2)$ statistical uncertainty, which verifies the assumption of no hysteresis in $\Delta H_{\text {tr }}, Q_{\text {step }, 0}, \sigma_{0}$, and $E_{\sigma}$ for ZIF-7. Meanwhile, our sister paper Rahman et al. ${ }^{42}$ examined the asymptotic dependence of the stepped isotherm hysteresis exhibited by $\mathrm{CO}_{2}$ on $\mathrm{ZIF}$ 7 at temperatures from $293 \mathrm{~K}$ down to $233 \mathrm{~K}$ and found that for both isotherm branches $\Delta H_{\mathrm{tr}}=$ 
$(31 \pm 2) \mathrm{kJ} \mathrm{mol}^{-1}$. Here in this work, over the higher temperature range (283 to 360) $\mathrm{K}$, the same result was obtained with $\Delta H_{\mathrm{tr}}=(28.6 \pm 0.7) \mathrm{kJ} \cdot \mathrm{mol}^{-1}$ if both branches are considered independently.
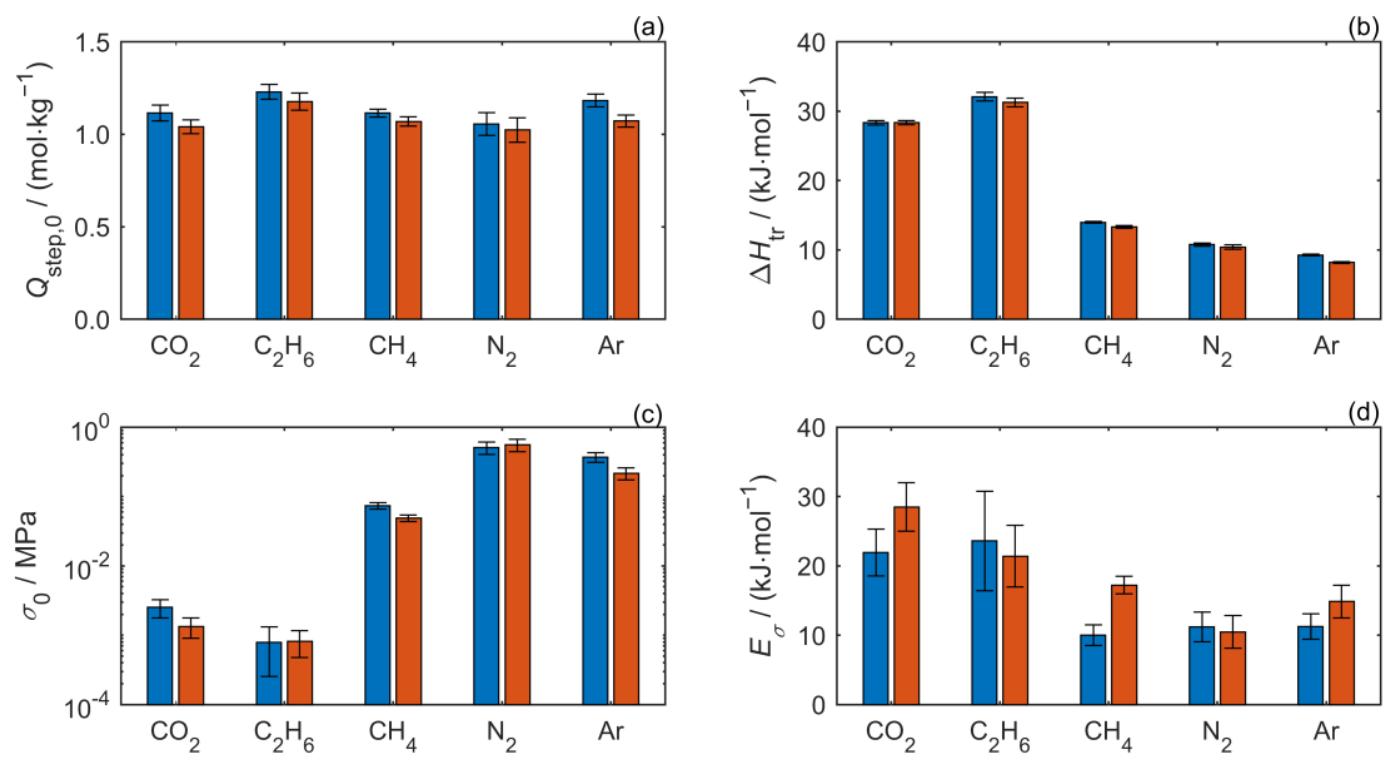

Figure 10. Best-fit values of the parameters $Q_{\text {step }, 0}, \Delta H_{\mathrm{tr}}, \sigma_{0}$, and $E_{\sigma}$ obtained for each adsorbate on ZIF-7 when the adsorption ( $\square$ ) and desorption ( $\square$ ) branches were regressed independently. The error bars denote the parameter's standard statistical uncertainty.

However, it is important to note that, the assumption of no hysteresis in $\Delta H_{\text {tr }}$ might not be true for some other materials. Our sister paper Rahman et al. ${ }^{42}$, using a simplified version of LJMYLangmuir model, found that some MOFs exhibit hysteresis in the transition enthalpy: for example the sorption data for $\mathrm{CH}_{4}$ on $\mathrm{Co}(\mathrm{bdp})$ of Mason et al. ${ }^{11}$ leads to $\Delta H_{t r}^{(\mathrm{ads})}=(9.1 \pm 0.3) \mathrm{kJ} \cdot \mathrm{mol}^{-1}$ and $\Delta H_{t r}^{(\text {des })}=(5.6 \pm 0.5) \mathrm{kJ} \cdot \mathrm{mol}^{-1}$. The isotherms measured by Couck et al. ${ }^{13}$ for $\mathrm{CO}_{2}$ on amino-MIL$53(\mathrm{Al})$ give values of $\Delta H_{t r}^{(\mathrm{ads})}=15 \mathrm{~kJ} \cdot \mathrm{mol}^{-1}$ and $\Delta H_{t r}^{(\mathrm{des})}=19 \mathrm{~kJ} \cdot \mathrm{mol}^{-1}$. Potentially, non-zero values of $\delta H_{t r} \equiv \Delta H_{t r}^{(\text {ads })}-\Delta H_{t r}^{(\text {des })}$ might reflect a combination of effects (e.g. structural transition plus pore filling/emptying) occurring simultaneously and/or asymmetrically along the isotherm's two branches. When the assumption of no hysteresis in parameters are not valid for the investigated material, we recommend fitting the adsorption and desorption branches separately to yield the best correlation.

At last, the intrinsic relations among parameters in the LJMY model were discussed. The transition width at the reference temperature $\sigma_{0}$ varies significantly across the five adsorbate gases on ZIF7 , reflecting in part the wide range of transition pressures: roughly speaking the more inert the adsorbate, the higher the transition pressure and the larger the transition width. The opposite 
pattern occurs for the enthalpy of the structural transition associated with each adsorbate: the more inert the adsorbate, the lower $\Delta H_{\text {tr. }}$ Figure 11 shows these two complementary patterns, between $\sigma_{0}$ and $\Delta H_{\mathrm{tr}}$ in terms of $p_{\mathrm{tr}, 0}{ }^{\text {(des) }}$. The relations among these three parameters could somehow be explained by the general model of porous materials proposed by Evans et al. ${ }^{43}$ According to their model, if the energy $\Delta H_{\mathrm{tr}}$, released due to the adsorption of gas, is adopted to overcome the energy barrier required for the structure change from np to lp, the higher $\Delta H_{\text {tr }}$ is, the smaller value and smaller range of the configurational activity ${ }^{43}$ or simply to say, pressure, is required, i.e., smaller values of $p_{\mathrm{tr}, 0}{ }^{(\mathrm{des})}$ and $\sigma_{0}$. A small discrepancy arises with argon having a larger $p_{\mathrm{tr}, 0}{ }^{(\mathrm{des})}$ than nitrogen but a smaller value of $\sigma_{0}$. No clear hysteresis was found for the transition width parameter for any adsorbate gas on ZIF-7, indicating that the both branches have the same ClausiusClapeyron temperature dependence (Figure 8(b)) characterized by the parameter $E_{\sigma}$ (which for $\mathrm{CO}_{2}$ on ZIF-7 $\left.\approx 26 \mathrm{~kJ} \cdot \mathrm{mol}^{-1}\right)$. However, Rahman et al. ${ }^{42}$ found that a clear hysteresis in $\sigma$ emerges with increasing temperature for $\mathrm{CH}_{4}$ on $\mathrm{Co}(\mathrm{bdp}) .{ }^{11}$ This corresponds to a relative difference of $64 \%$ in $E_{\sigma}$ for the two branches that is even more significant than the relative difference in $\Delta H_{\mathrm{tr}}$ of $32 \%$ for this MOF-adsorbate pair.

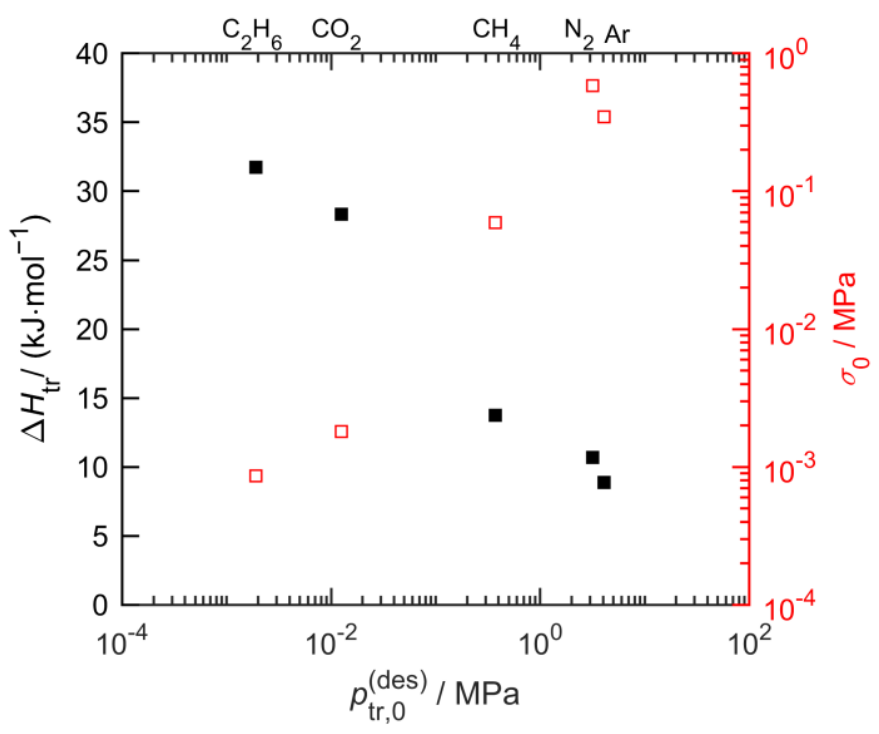

Figure 11. Variations of $\Delta H_{\mathrm{tr}}(\mathbf{\bullet})$ and $\sigma_{0}(\square)$ with the threshold pressure $p_{\mathrm{tr}, 0}{ }^{(\mathrm{des})}$.

\section{Conclusions}

Stepped hysteretic sorption isotherms were experimentally observed for nitrogen, argon, ethane, carbon dioxide and methane at temperatures from 283 to $359 \mathrm{~K}$ with pressures up to $17 \mathrm{MPa}$ on 
zeolitic imidazolate framework-7 (ZIF-7). Isotherms for carbon dioxide, methane and ethane on ZIF-7 were consistent with observations reported in the literature, while those for nitrogen and argon have not been previously reported. The transition pressures at which the adsorption isotherms exhibit pronounced steps for nitrogen and argon on ZIF-7 is around (5 to $15 \mathrm{MPa}$ ), which is much higher than for $\mathrm{CO}_{2}$ and ethane $(<0.4 \mathrm{MPa})$ or methane (1 to $2.5 \mathrm{MPa}$ ). Inert molecules are thus able to trigger the structural phase transition of ZIF-7 at ambient temperatures if the pressure is sufficiently high. The measurements were carried out with a gravimetric sorption analyzer with the combined expanded measurement uncertainty $(k=2)$ of the sorption capacity estimated to range from $0.006 \mathrm{~mol} \cdot \mathrm{kg}^{-1}$ at the lowest pressures to $0.159 \mathrm{~mol} \cdot \mathrm{kg}^{-1}$ at the highest pressures.

To describe the stepped hysteretic sorption isotherms measured in this work and reported for other MOFs in literature, a new, fully-temperature dependent model was developed. Known as the LJMY-Langmuir model because it uses the Langmuir equation to describe the Type I sorption behavior, with the LJMY model representing the MOF's structural phase transition in terms of a distribution of pores with varying transition pressures. The new model fits the measured data well with root-mean-square deviations within $2.5 \%$ of the maximum adsorption capacity. For ZIF-7 key parameters describing the adsorption and desorption branches could be constrained to have the same value and still provide an excellent correlation of the hysteretic stepped sorption: multiple hysteretic isotherms measured over an $80 \mathrm{~K}$ temperature range and $10 \mathrm{MPa}$ pressure range could be described with a maximum of only ten adjustable parameters. Each parameter of the LJMYLangmuir model has a physical basis, which allows some of them to be fixed in the regression at values estimated from independent sources, and provides the resulting best-fit values to be interpreted in terms of the MOF-adsorbate interactions.

\section{Acknowledgements}

The authors are grateful the Australian Research Council for funding this research through DP190100983 and IC150100019. 


\section{References}

1. Furukawa, H.; Cordova, K. E.; O’Keeffe, M.; Yaghi, O. M., The Chemistry and Applications of Metal-Organic Frameworks. Science 2013, 341 (6149).

2. $\quad$ Li, H.; Wang, K.; Sun, Y.; Lollar, C. T.; Li, J.; Zhou, H.-C., Recent advances in gas storage and separation using metal-organic frameworks. Materials Today 2018, 21 (2), 108-121.

3. Bao, Z.; Chang, G.; Xing, H.; Krishna, R.; Ren, Q.; Chen, B., Potential of microporous metal-organic frameworks for separation of hydrocarbon mixtures. Energy \& Environmental Science 2016, 9 (12), 3612-3641.

4. $\quad$ Alaerts, L.; Kirschhock, C. E. A.; Maes, M.; van der Veen, M. A.; Finsy, V.; Depla, A.; Martens, J. A.; Baron, G. V.; Jacobs, P. A.; Denayer, J. F. M.; De Vos, D. E., Selective Adsorption and Separation of Xylene Isomers and Ethylbenzene with the Microporous Vanadium(IV) Terephthalate MIL-47. Angewandte Chemie International Edition 2007, 46 (23), 4293-4297.

5. Horcajada, P.; Serre, C.; Vallet-Regí, M.; Sebban, M.; Taulelle, F.; Férey, G., MetalOrganic Frameworks as Efficient Materials for Drug Delivery. Angewandte Chemie International Edition 2006, 45 (36), 5974-5978.

6. Schneemann, A.; Bon, V.; Schwedler, I.; Senkovska, I.; Kaskel, S.; Fischer, R. A., Flexible metal-organic frameworks. Chemical Society Reviews 2014, 43 (16), 6062-6096.

7. Gao, S.; Morris, C. G.; Lu, Z.; Yan, Y.; Godfrey, H. G. W.; Murray, C.; Tang, C. C.; Thomas, K. M.; Yang, S.; Schröder, M., Selective Hysteretic Sorption of Light Hydrocarbons in a Flexible Metal-Organic Framework Material. Chemistry of Materials 2016, 28 (7), 2331-2340.

8. Li, J.-R.; Kuppler, R. J.; Zhou, H.-C., Selective gas adsorption and separation in metalorganic frameworks. Chemical Society Reviews 2009, 38 (5), 1477-1504.

9. $\quad$ Mason, J. A.; Oktawiec, J.; Taylor, M. K.; Hudson, M. R.; Rodriguez, J.; Bachman, J. E.; Gonzalez, M. I.; Cervellino, A.; Guagliardi, A.; Brown, C. M.; Llewellyn, P. L.; Masciocchi, N.; Long, J. R., Methane storage in flexible metal-organic frameworks with intrinsic thermal management. Nature 2015, 527 (7578), 357-361.

10. Arami-Niya, A.; Birkett, G.; Zhu, Z.; Rufford, T. E., Gate opening effect of zeolitic imidazolate framework ZIF-7 for adsorption of $\mathrm{CH}_{4}$ and $\mathrm{CO}_{2}$ from $\mathrm{N}_{2}$. J. Mater. Chem. A 2017, 5 (40), 21389-21399.

11. Mason, J. A.; Oktawiec, J.; Taylor, M. K.; Hudson, M. R.; Rodriguez, J.; Bachman, J. E.; Gonzalez, M. I.; Cervellino, A.; Guagliardi, A.; Brown, C. M., Methane storage in flexible metalorganic frameworks with intrinsic thermal management. Nature 2015, 527 (7578), 357-361.

12. McDonald, T. M.; Mason, J. A.; Kong, X.; Bloch, E. D.; Gygi, D.; Dani, A.; Crocella, V.; Giordanino, F.; Odoh, S. O.; Drisdell, W. S., Cooperative insertion of CO 2 in diamine-appended metal-organic frameworks. Nature 2015, 519 (7543), 303.

13. Couck, S.; Denayer, J. F. M.; Baron, G. V.; Rémy, T.; Gascon, J.; Kapteijn, F., An aminefunctionalized MIL-53 metal- organic framework with large separation power for $\mathrm{CO} 2$ and $\mathrm{CH} 4$. JACS 2009, 131 (18), 6326-6327.

14. Cai, W.; Lee, T.; Lee, M.; Cho, W.; Han, D.-Y.; Choi, N.; Yip, A. C. K.; Choi, J., Thermal structural transitions and carbon dioxide adsorption properties of zeolitic imidazolate framework7 (ZIF-7). JACS 2014, 136 (22), 7961-7971.

15. Gücüyener, C.; van den Bergh, J.; Gascon, J.; Kapteijn, F., Ethane/ethene separation turned on its head: selective ethane adsorption on the metal- organic Framework ZIF-7 through a gateopening mechanism. JACS 2010, 132 (50), 17704-17706. 
16. Sips, R., On the structure of a catalyst surface. J. Chem. Phys. 1948, 16 (5), 490-495.

17. Toth, J., State equation of the solid-gas interface layers. Acta chim. hung. 1971, 69, 311328.

18. Coudert, F.-X.; Jeffroy, M.; Fuchs, A. H.; Boutin, A.; Mellot-Draznieks, C., Thermodynamics of guest-induced structural transitions in hybrid organic- inorganic frameworks. JACS 2008, 130 (43), 14294-14302.

19. Li, G.; Shang, J.; Gu, Q.; Awati, R. V.; Jensen, N.; Grant, A.; Zhang, X.; Sholl, D. S.; Liu, J. Z.; Webley, P. A.; May, E. F., Temperature-regulated guest admission and release in microporous materials. Nature Communications 2017, 8 (1), 15777.

20. Park, K. S.; Ni, Z.; Côté, A. P.; Choi, J. Y.; Huang, R.; Uribe-Romo, F. J.; Chae, H. K.; O'Keeffe, M.; Yaghi, O. M., Exceptional chemical and thermal stability of zeolitic imidazolate frameworks. Proc. Natl. Acad. Sci. U.S.A. 2006, 103 (27), 10186-10191.

21. Cavenati, S.; Grande, C. A.; Rodrigues, A. E., Adsorption equilibrium of methane, carbon dioxide, and nitrogen on zeolite $13 X$ at high pressures. J. Chem. Eng. Data 2004, 49 (4), 10951101.

22. Dreisbach, F.; Lösch, H. W., Magnetic suspension balance for simultaneous measurement of a sample and the density of the measuring fluid. J. Therm. Anal. Calorim. 2000, 62 (2), 515521.

23. Hefti, M.; Marx, D.; Joss, L.; Mazzotti, M., Adsorption equilibrium of binary mixtures of carbon dioxide and nitrogen on zeolites ZSM-5 and 13X. Microporous Mesoporous Mater. 2015, 215, 215-228.

24. May, E. F.; Miller, R. C.; Shan, Z., Densities and dew points of vapor mixtures of methane+ propane and methane+ propane+ hexane using a dual-sinker densimeter. J. Chem. Eng. Data 2001, 46 (5), 1160-1166.

25. Yang, X.; Richter, M., Experimental Investigation of Surface Phenomena on Quasi Nonporous and Porous Materials Near Dew Points of Pure Fluids and Their Mixtures. Ind. Eng. Chem. Res. 2020, 59 (7), 3238-3251.

26. Kleinrahm, R.; Yang, X.; McLinden, M. O.; Richter, M., Analysis of the systematic forcetransmission error of the magnetic-suspension coupling in single-sinker densimeters and commercial gravimetric sorption analyzers. Adsorption 2019, 1-19.

27. Yang, X.; Kleinrahm, R.; McLinden, M. O.; Richter, M., Uncertainty analysis of adsorption measurements with commercial gravimetric sorption analyzers with simultaneous density measurements based on a magnetic-suspension balance. Adsorption 2020, (accepted).

28. Span, R.; Wagner, W., A new equation of state for carbon dioxide covering the fluid region from the triple-point temperature to $1100 \mathrm{~K}$ at pressures up to $800 \mathrm{MPa}$. J. Phys. Chem. Ref. Data 1996, 25 (6), 1509-1596.

29. Bücker, D.; Wagner, W., A reference equation of state for the thermodynamic properties of ethane for temperatures from the melting line to $675 \mathrm{~K}$ and pressures up to $900 \mathrm{MPa}$. J. Phys. Chem. Ref. Data 2006, 35 (1), 205-266.

30. Span, R.; Lemmon, E. W.; Jacobsen, R. T.; Wagner, W.; Yokozeki, A., A reference equation of state for the thermodynamic properties of nitrogen for temperatures from 63.151 to $1000 \mathrm{~K}$ and pressures to $2200 \mathrm{MPa}$. J. Phys. Chem. Ref. Data 2000, 29 (6), 1361-1433.

31. Setzmann, U.; Wagner, W., A new equation of state and tables of thermodynamic properties for methane covering the range from the melting line to $625 \mathrm{~K}$ at pressures up to 100 MPa. J. Phys. Chem. Ref. Data 1991, 20 (6), 1061-1155. 
32. Tegeler, C.; Span, R.; Wagner, W., A new equation of state for argon covering the fluid region for temperatures from the melting line to $700 \mathrm{~K}$ at pressures up to $1000 \mathrm{MPa}$. J. Phys. Chem. Ref. Data 1999, 28 (3), 779-850.

33. Lemmon, E. W.; Bell, I. H.; Huber, M. L.; McLinden, M. O., NIST Standard Reference Database 23: Reference Fluid Thermodynamic and Transport Properties-REFPROP, Version 10.0, National Institute of Standards and Technology, 2017. URL http://www.nist.gov/srd/nist23.cfm.

34. McLinden, M. O.; Kleinrahm, R.; Wagner, W., Force transmission errors in magnetic suspension densimeters. Int. J. Thermophys. 2007, 28 (2), 429-448.

35. ISO/IEC Guide 98-3 Uncertainty of measurement - Part 3: Guide to the expression of uncertainty in measurement (GUM:1995). International Organization for Standardization, Geneva, 2008.

36. van den Bergh, J.; Gücüyener, C.; Pidko, E. A.; Hensen, E. J. M.; Gascon, J.; Kapteijn, F., Understanding the anomalous alkane selectivity of ZIF - 7 in the separation of light alkane/alkene mixtures. Chemistry - A European Journal 2011, 17 (32), 8832-8840.

37. Trowbridge, A. J.; Melosh, H. J.; Steckloff, J. K.; Freed, A. M., Vigorous convection as the explanation for Pluto's polygonal terrain. Nature 2016, 534 (7605), 79.

38. Peterson, O. G.; Batchelder, D. N.; Simmons, R. O., Measurements of X-ray lattice constant, thermal expansivity, and isothermal compressibility of argon crystals. Phys. Rev. 1966, 150 (2), 703.

39. Manzhelii, V. G.; Tolkachev, A. M.; Bagatskii, M. I.; Voitovich, E. I., Thermal expansion, heat capacity, and compressibility of solid CO2. Phys. Status Solidi B 1971, 44 (1), 39-49.

40. Klimenko, N. A.; Gal'Tsov, N. N.; Prokhvatilov, A. I., Structure, phase transitions, and thermal expansion of ethane C 2 H 6. Low Temp. Phys. 2008, 34 (12), 1038-1043.

41. Manzhelii, V. G.; Tolkachev, A. M.; Gavrilko, V. G., Thermal expansion of solid CH4 and CD4. J. Phys. Chem. Solids 1969, 30 (12), 2759-2763.

42. Rahman, S.; Arami-Niya, A.; Yang, X.; Xiao, G.; Li, G. K.; May, E. F., Temperature Dependence of Adsorption Hysteresis in Flexible Metal Organic Frameworks JACS 2020, (submitted).

43. Evans, J. D.; Krause, S.; Kaskel, S.; Sweatman, M. B.; Sarkisov, L., Exploring the thermodynamic criteria for responsive adsorption processes. Chemical science 2019, 10 (19), 5011-5017. 


\section{Table of Contents}

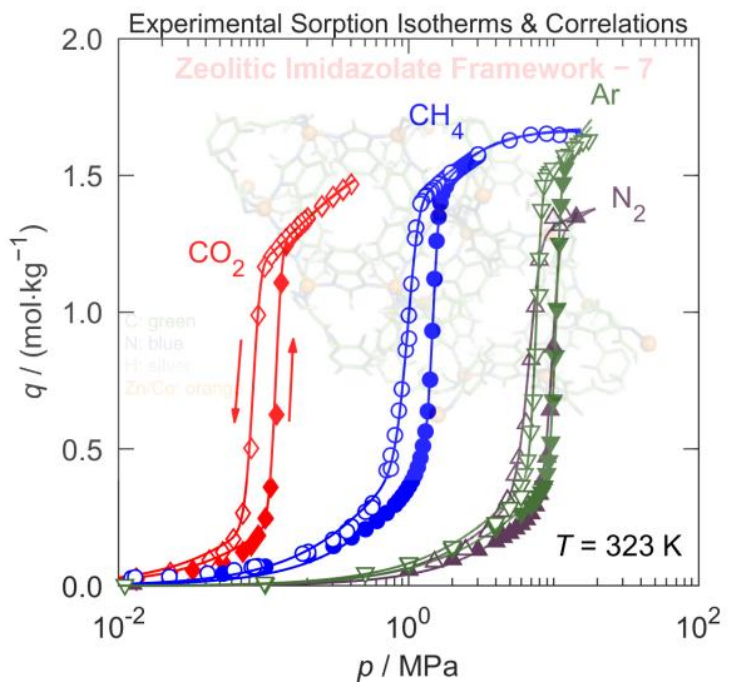

